\title{
Aggregation of the reef-building tube worm Filogranella elatensis at Semporna, eastern Sabah, Malaysia
}
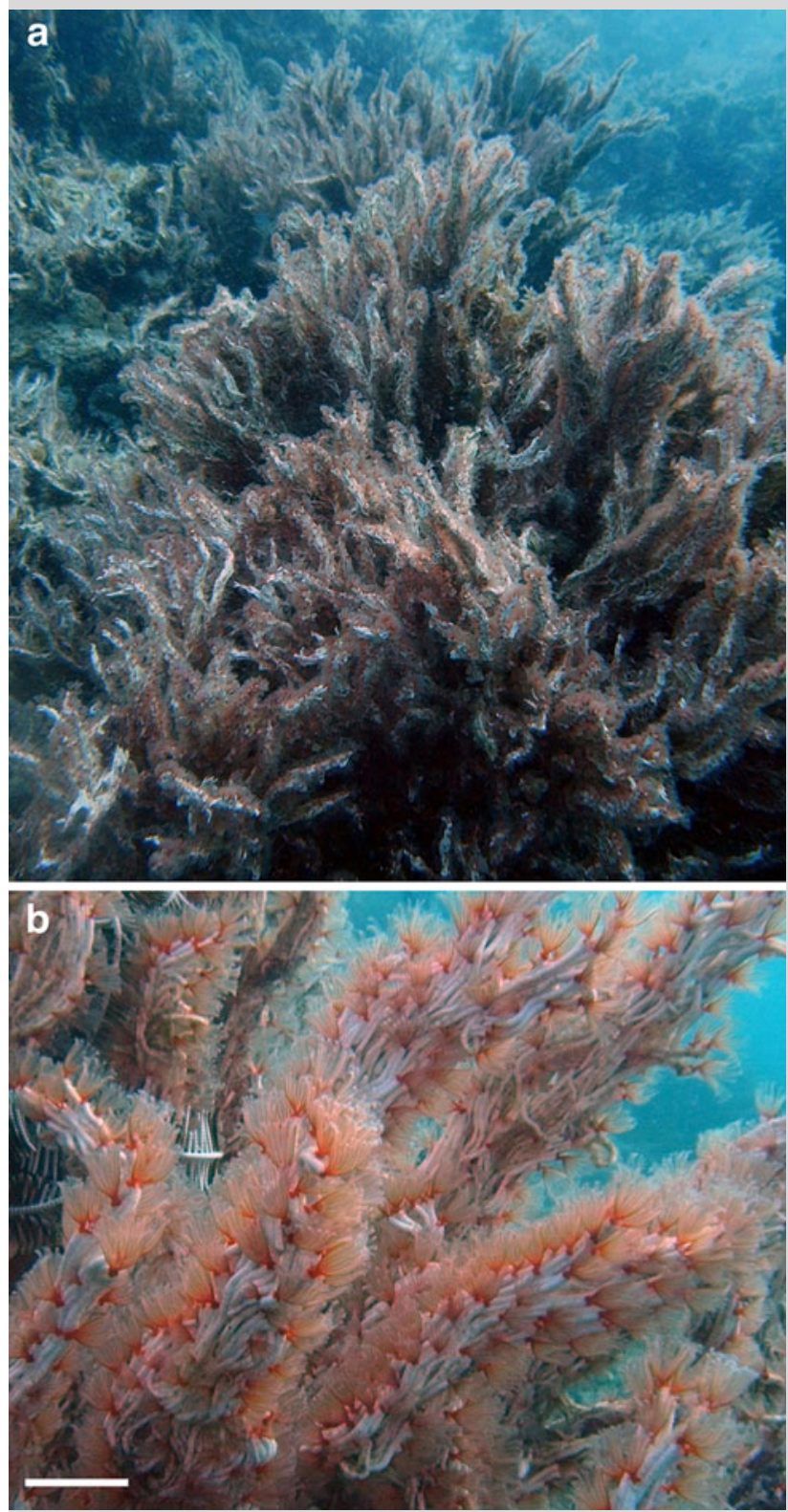

Fig. 1 Filogranella elatensis at Bakungan I., eastern Sabah. a Field of variable height with hummocky appearance. b Close-up: bundles of tubes. Scale bar: $2 \mathrm{~cm}$
During the Semporna Marine Ecological Expedition in eastern Sabah (SMEE2010), a large field (ca. $15 \mathrm{~m}$ long, 3-6 m wide, with a cover of $75-100 \%$ ) of the reef-building tube worm Filogranella elatensis Ben-Eliahu and Dafni, 1979 (Polychaeta: Serpulidae) was encountered on 16 December 2010 along the sheltered upper reef slope of Bakungan I. (N 04 $45^{\prime} 11^{\prime \prime}$, E $118^{\circ} 29^{\prime} 16^{\prime \prime}$ ), Darvel Bay, Semporna region, Malaysia (Fig. 1). The aggregation was fragmented and had an overall hummocky appearance. Its depth range varied between 3 and $7 \mathrm{~m}$ and its maximum height was approximately $50-60 \mathrm{~cm}$. The various parts of the aggregation did not appear to be attached to the predominantly sandy substrate. As such, the morphology of these "reefs" is reminiscent of aggregations of the genus Serpula from temperate and cold waters (Ten Hove and Van den Hurk 1993).

Aggregations of this species are not uncommon (Ten Hove and Kupriyanova 2009) but previously they have not been reported to cover a large area of this size. The first record concerns a colony of $1.5 \mathrm{~m}$ wide, described by Ben-Eliahu and Dafni (1979), who suggested that aggregations in these serpulids may be related to pollution and a result of asexual reproduction. However, records from unpolluted areas are also known (Ten Hove and Van den Hurk 1993) and although the reef site in Darvel Bay did not show high coral cover, there was no direct indication for pollution. Similar to previously described serpulid aggregations, this field of tube worms was found in a sheltered habitat.

Acknowledgments WWF Malaysia organized SMEE2010. Research permits were issued by Sabah Parks and the Economic Planning Unit, Prime Minister's Department, Malaysia.

Open Access This article is distributed under the terms of the Creative Commons Attribution Noncommercial License which permits any noncommercial use, distribution, and reproduction in any medium, provided the original author(s) and source are credited.

\section{References}

Ben-Eliahu MN, Dafni J (1979) A new reef-building serpulid genus and species from the Gulf of Elat and the Red Sea, with notes on other gregarious tubeworms from Israeli waters. Isr J Zool 28:199-208

Ten Hove HA, Kupriyanova EK (2009) Taxonomy of Serpulidae (Annelida, Polychaeta): The state of affairs. Zootaxa 2036:1-126

Ten Hove HA, Van den Hurk P (1993) A review of Recent and fossil serpulid "reefs"; actuopaleontology and the 'Upper Malm' serpulid limestones in NW Germany. Geol Mijnb 72:23-67

B. W. Hoeksema $(\bowtie)$

Department of Marine Zoology, Netherlands Center for Biodiversity Naturalis, P.O. Box 9517, 2300 RA Leiden, The Netherlands e-mail: bert.hoeksema@ncbnaturalis.nl

H. A. Ten Hove

Netherlands Center for Biodiversity Naturalis (Section ZMA), University of Amsterdam, P.O. Box 94766, 1090 GT Amsterdam, The Netherlands

Received: 15 April 2011/ Accepted: 18 May 2011/Published online: 23 June 2011

Coral Reefs (2011) 30:839

(C) The Author(s) 2011. This article is published with open access at Springerlink.com DOI $10.1007 / \mathrm{s} 00338-011-0785-8$ 